\title{
Comparison Contour Extraction Based on Layered Structure and Fourier Descriptor on Image Retrieval
}

\author{
Cahya Rahmad \\ Departemen of Information Technology \\ State Polytechnics of Malang \\ Malang East Java, Indonesia
}

\author{
Kohei Arai \\ Graduate School of Science and Engineering \\ Saga University \\ Saga City, Japan
}

\begin{abstract}
In this paper, a new content-based image retrieval technique using shape feature is proposed. A shape features extracted by layered structure representation has been implemented. The approach is extract feature shape by measuring the distance between centroid (center) and boundaries of the object that can capture multiple boundaries in the same angle, an object shape that has some points with the same angle.Once an input taking into account, the method will search most related image to the input. The correlation between input and output has been defined by specific role. Firstly the input image has to be converted from RGB image to Grayscale image and then follow by edge detection process. After edge detection process the boundary object will be obtained and then calculate the distance between the center of an object and the boundary of an object and put it in the feature vector and if there is another boundary on the same angle then put it in the different feature vector with a different layer. The experiment result on the plankton dataset shows that the proposed method better than other conventional Fourier descriptor method.
\end{abstract}

Keywords-Cbir; Mlccd; extract features; rgb; Fourier descriptor; shape; retrieval

\section{INTRODUCTION}

The Content-Based Image Retrieval (CBIR) technique uses image content to search and retrieve digital images. Basically, CBIR systems try to retrieve images similar to a user-defined specification or pattern (e.g., shape sketch, image example). Their goal is to support image retrieval based on content properties (e.g., shape, color, texture) [1], CBIR is also based on the idea of extracting visual features from the image and using them to index images in a database. Contentbased image retrieval systems were introduced to address the problems associated with text-based image retrieval. CBIR is a set of techniques for retrieving semantically-relevant images from an image database based on automatically-derived image features[2]. Content-based image retrieval also known as query by image content is a technique which uses visual content that well known as features for extracting similar images from an image in a database[3][4][5]. Image database every time become bigger and it makes a problem dealing with database organization so the necessity of efficient algorithm is obvious needed [6].

On The Content-based Image Retrieval local feature of an image is computed at some point of interest location. In order to recognize the object firstly the image has to be represented by a feature vector. These feature vectors are converted to a different domain to make simple and efficient image characteristic, classification and indexing. Many techniques to extract the image feature is proposed [7][8][9][10].

The shape is one of the primary features in Content-Based Image Retrieval (CBIR). The shape is also one of an important visual feature of an image and used to describe image content. Among them is methods based Fourier descriptors (FDs), Fourier descriptors are obtained by applying Fourier transform on shape boundary, The concept of Fourier descriptor (FD) has been widely used in the field of computational shape analysis Fourier descriptor [11] [12]. The idea of the FD (Fourier Descriptor) is to use the Fourier transformed boundary as a shape Feature. Suppose a shape signature Z(u) is a 1-D function that represents 2-D areas or boundaries. The discrete Fourier transform of a signature $\mathrm{z}(\mathrm{u})$ is defined as follows:

$$
a_{n}=\frac{1}{N} \sum_{u=0}^{N-1} Z(u) e^{-j 2 \pi n u / N}
$$

where $n=0,1,2, \ldots n-1$. The coefficients $a_{n}(n=0,1, . . N-1)$ are called the Fourier descriptors (FDs) of the shape.

\section{PRoposed Method}

The algorithm of proposed method is described as follow:

1) Input image from database image / Query Image

2) Convert RGB image To Gray Image

3) Edge detection

4) Morphology Filter

5) Construct feature vector using multi-layer centroid contour distance (MLCCD)

6) Comparison for similarity retrieval

7) Display Result based on distance measure

Image from database image or from query image convert from RGB image into Grayscale image then implement the canny filter to detect edge position then use morphology filter to ensure the shape of object clear. Then local feature of an image at some point at interest location is computed. The feature vector is computed by measuring a distance between a center of object and point in the boundary object Then the result is placed to the feature vector layer by layer (see fig.1). and then the feature vector that obtained from database image and Query Image be compared each other (similarity process) then display the result. The retrieval result is not a single image but a list of image ranked by their similarity. in these 
case if the distance between feature representation of an image in database image and feature representation of image query small enough then it to be considered as similar.

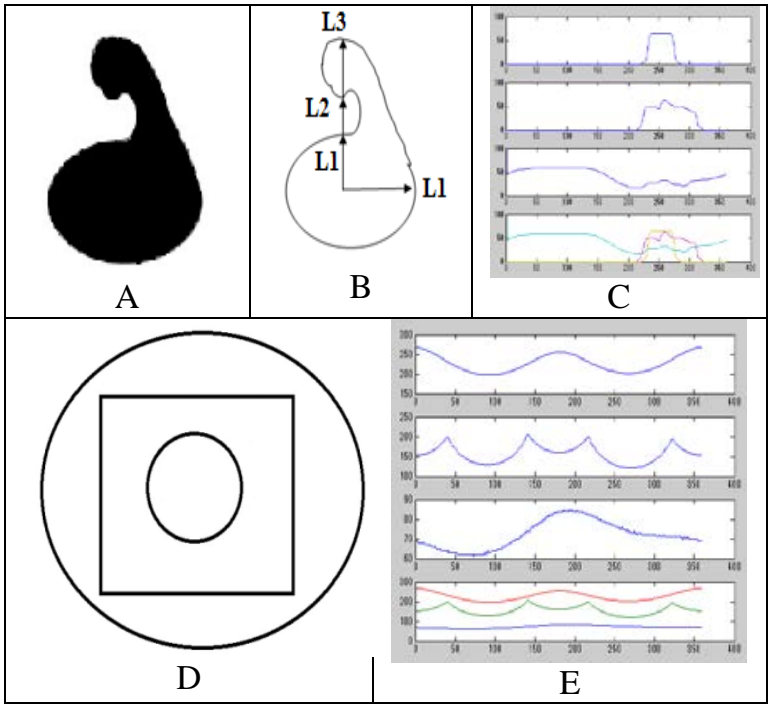

Fig. 1. An object and its feature vector layer by layer

Figure 1A is example object before edge detection process. Figure $1 \mathrm{~B}$ is a boundary of an object after edge detection process, when the angle 0 there is one point have to be captured, the distance between centroid and boundary object is placed in the layer one. However, when the angle is 270 degree there are three points have to be captured (clockwise direction), the distance between centroid and boundary object is placed in the layer one, layer two and layer three (see figure 1C). Figure 1D is example shape of an object with tree point for every angle. Similarly, the distance between centroid and boundary object in the Figure $1 \mathrm{D}$ is placed in the layer one, layer two and layer three (see Figure 1E).

In order to obtain the MLCCD firstly position of the centroid have to be computed (see equation 1) then calculate the distance between the centroid and the boundary of an object by using Euclidean distance, see equation 2) repeat this method for another boundary in the same angle and different angle.

The position of the centroid is:

$X_{c}=\frac{X_{1}+X_{2}+X_{3}+\ldots .+X_{n}}{n}, \quad Y_{c}=\frac{Y_{1}+Y_{2}+Y_{3}+\ldots+Y_{n}}{n}$

where:

$\mathrm{X}_{\mathrm{C}}=$ position of the centroid in the $\mathrm{x}$ axis

$\mathrm{Y}_{\mathrm{C}}=$ position of the centroid in the $\mathrm{y}$ axis

$\mathrm{n}=$ Total point in the object

(every point have $\mathrm{x}$ position and y position)

After the centroid was obtained then calculate a distance between centroid to every point in the boundary, Suppose there is t point in the boundary of an object the distance every point in the boundary with centroid is:

where:

$$
\operatorname{Dis}(n)=\sqrt{\left(x(n)-x_{c}\right)^{2}+\left(y(n)-y_{c}\right)^{2}}
$$

$\mathrm{n} \quad=$ number point in the boundary of object $(1,2, . . \mathrm{t})$ $\mathrm{t}=$ total point in the boundary

$x_{c}=$ position center in the $\mathrm{x}$ axis

$y_{c}=$ position center in the $\mathrm{y}$ axis

$\mathrm{x}(\mathrm{n})=$ position point number $\mathrm{n}$ in the $\mathrm{x}$ axis

$y(n)=$ position point number $n$ in the $y$ axis

The computed distances are saved in a vector layer by layer. In order to achieve rotation invariance, scale invariance and translation invariance implementation shifting and normalization to this vector is needed.

\section{SIMILARITY AND PERFORMANCE}

To test the effectiveness of the approach, the similarity and performance measure is conducted. The comparisons that determine a similarity between images depend on the representations of the features and the definition of an appropriate distance function. The similarity metric is very important on the retrieval result.

The similarity measure is computed by using Euclidean distance (See Equation 3) between feature representation of an image in database image and feature representation of image query. This feature representation is image feature that refer to the characteristics which describe the contents of an image.

The retrieval result is a list of image ranked by their similarity. Suppose S1 and S2 are shape of object represented layer by layer of feature vectors each (Q1, Q2,...,Qn) and (D1, $\mathrm{D} 2, \ldots, \mathrm{Dn})$ then the Distance between S1 and S2 is:

$$
\operatorname{dis}(F Q, F D)=\sqrt{\sum_{j=1}^{n}(Q j-D j)^{2}}
$$

where:

$\mathrm{FQ}=$ Feature vector of a query image .

$\mathrm{FD}=$ Feature vector of image in dataset

$\mathrm{n}=$ Number element of the feature vector

If the distance between feature representation of image query and feature representation of an image in dataset small enough then it to be considered as similar, For example, a distance of 0 have meant an exact match with the query and 1 mean totally different. Base the ranked of that similarity then the retrieval results be displayed.

The performance of Content-Based Image Retrieval: CBIR system is calculated by showing an image with $\mathrm{X}$ top ranking from the dataset. Precision is The common way method to evaluate the performance of the CBIR system, Formula Precision is:

$$
\text { Precision }=\frac{\text { Number of relevant images retrieved }}{\text { Total number of images retrieved }}
$$

The precision measures the retrieval accuracy, it is the ratio between the number of relevant images retrieved and the total number of images retrieved (See Equation 4).

\section{EXPERIMENT AND ANALYSIS}

Image database of phytoplankton [13] for experiment to real data In order to show the feasibility of the shape recognition scheme is used. Red tide occurs in a nutrition rich ocean. Nutrition rich water makes chlorophyll-a then 
phytoplankton is increase thus red tide occurs. Algal blooms (red tides) are a phenomenon of clear ecological importance in many regions of the world.

Caused by a nutrient influx (e.g. agricultural pollution) into the ocean, by either natural or anthropogenic causes, Red tide can be toxic to marine life and humans under certain conditions. They are a significant problem not only for fisherman but also ocean biologist. Red tide is one of measure for representation of ocean healthy[14] [15].

Figure 2 shows Example of phytoplankton image. In order to detect red tide, many researchers check phytoplankton in water sampled from the ocean with a microscope. Immediately after they check phytoplankton, they have to identify the species of phytoplankton. Image retrieval is needed for identification. The proposed method is to be used for image retrieval and identification.

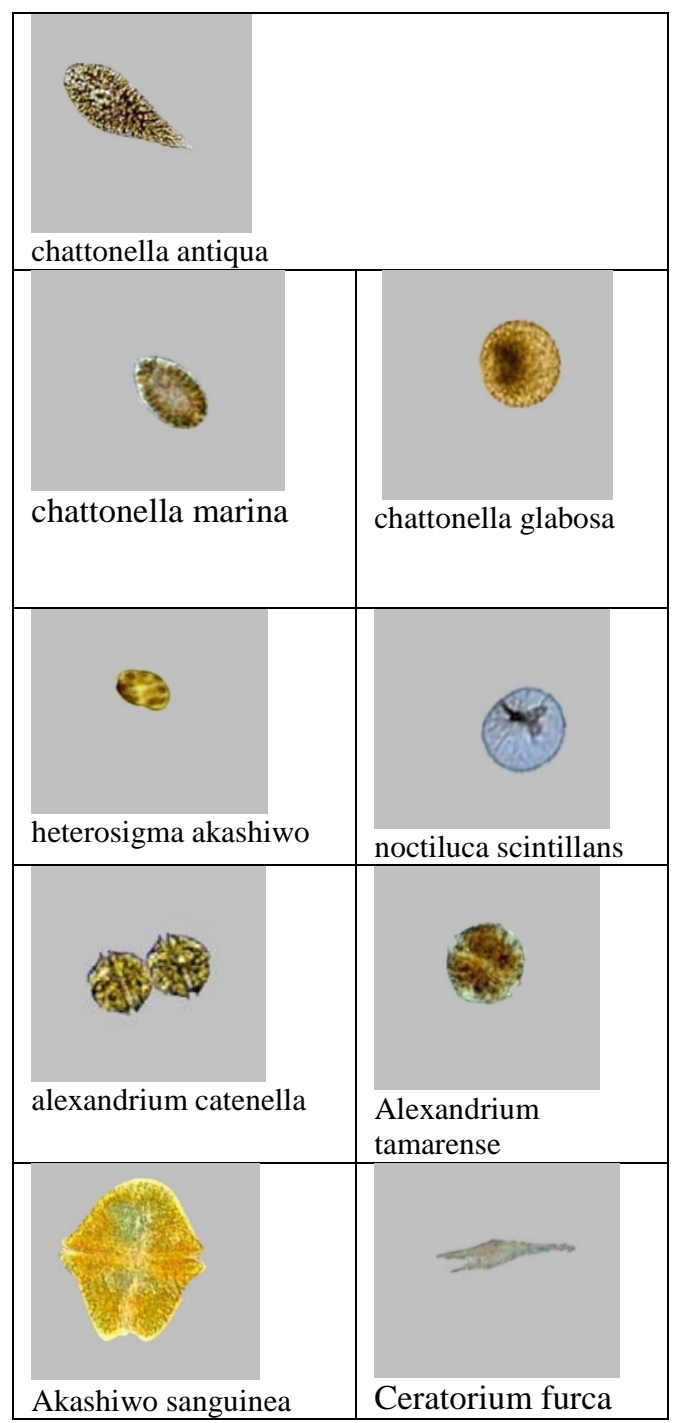

Fig. 2. Example of phytoplankton image
TABlE I. Average PRECISION ON Phytoplankton Dataset

\begin{tabular}{|l|l|l|l|l|}
\hline $\begin{array}{l}\text { Number } \\
\text { Group }\end{array}$ & $\begin{array}{l}\text { Total } \\
\text { Image }\end{array}$ & $\begin{array}{l}\text { Phytoplankton } \\
\text { name }\end{array}$ & $\begin{array}{l}\text { Fourier } \\
\text { descriptor }\end{array}$ & $\begin{array}{l}\text { Proposed } \\
\text { Method }\end{array}$ \\
\hline 1 & 18 & $\begin{array}{l}\text { chattonella } \\
\text { antiqua }\end{array}$ & 85 & 91 \\
\hline 2 & 17 & $\begin{array}{l}\text { chattonella } \\
\text { marina }\end{array}$ & 86 & 90 \\
\hline 3 & 17 & $\begin{array}{l}\text { chattonella } \\
\text { glabosa }\end{array}$ & 83 & 87 \\
\hline 4 & 17 & $\begin{array}{l}\text { heterosigma } \\
\text { akashiwo }\end{array}$ & 84 & 88 \\
\hline 5 & 17 & $\begin{array}{l}\text { noctiluca } \\
\text { scintillans } \\
\text { alexandrium } \\
\text { catenella }\end{array}$ & 84 & 87 \\
\hline 6 & 20 & $\begin{array}{l}\text { Alexandrium } \\
\text { tamarense }\end{array}$ & 84 & 94 \\
\hline 8 & 23 & $\begin{array}{l}\text { Akashiwo } \\
\text { sanguinea }\end{array}$ & 85 & 93 \\
\hline 9 & 24 & $\begin{array}{l}\text { Ceratorium } \\
\text { furca }\end{array}$ & 83 & 94 \\
\hline \multicolumn{5}{|l|}{ Average } \\
\hline
\end{tabular}

The experiment on phytoplankton image dataset in Table 1 is precision measure base on equation 5, Average precision result by using the proposed method is higher 3 percent (see in group 5) up to 11 percent (see in group 9) rather than another method. From this table and figure, it may say that the proposed method is superior to the conventional method for all cases by approximately $6.444 \%$.

\section{CONCLUSION}

In The comparison between the proposed contour extraction based on layered structure representation and the Fourier descriptor based on image retrieval have propose a new approach to extract features of an object shape that have some points with the same angle.

a novel approach feature shape by measuring a distance between centroid (center) and a boundary of an object that can capture multiple boundaries in the same angle is developed. The experiment results on phytoplankton dataset demonstrate a new approach better than another method. the proposed method is superior to the conventional method for all cases by approximately $6.444 \%$.

\section{REFERENCES}

[1] João Augusto da Silva Júnior, Rodiney Elias Marçal, Marcos Aurélio Batista,”Image Retrieval: Importance and Applications ”, Workshop de Vis ao Computacional - WVC 2014.

[2] F. Long, H. Zhang, and D. Feng, "Fundamentals of content based image retrieval," "Multimedia Information Retrieval and Management. Technological Fundamentals and Applications,"Multimedia Signal Processing Book, Chapter 1, Springer-Verlag, Berlin Heidelberg New York, pp. 1-26, 2003.

[3] R. Datta, D. Joshi, J. Li, and J. Z. Wang, "Image retrieval: Ideas, influences, and trends of the new age," ACM Computing Surveys, vol. 40, no. 2, pp. 1-60, Apr. 2008.

[4] C. Carson and S. Belongie, "Blobworld: Image segmentation using expectation-maximization and its application to image querying," Pattern Analysis and ..., 2002. 
[5] P. B. Thawari and N. J. Janwe, "CBIR BASED ON COLOR AND TEXTURE,” vol. 4, no. 1, pp. 129-132, 2011.

[6] FotopoulouF and EconomouG, "Multivariate angle scale descriptor of shape retrieval," Proc. Signal. Process Appl. Math. Electron ..., pp. 105-108, 2011.

[7] Y. Liu, D. Zhang, G. Lu, and W.-Y. Ma, "A survey of content-based image retrieval with high-level semantics," Pattern Recognition, vol. 40, no. 1, pp. 262-282, Jan. 2007.

[8] N. Singhai and S. K. Shandilya, "A Survey On: Content Based Image Retrieval Systems," International Journal of Computer Applications, vol. 4, no. 2, 2010.

[9] D. Zhang and G. Lu, "Review of shape representation and description techniques," Pattern Recognition, vol. 37, no. 1, pp. 1-19, Jan. 2004.

[10] D. Zhang and G. Lu, "A Comparative Study of Three Region Shape Descriptors,” no. January, pp. 1-6, 2002.

[11] FUNTOURA Costa and C. R. M., "Shape Analysis and Classifica tion: Theory and Practice,” Boca Raton, FL.: CRC Press, 2001.

[12] W. Jun, G. E. Q. Jeffrey, G. Feng, and S. Hai-Jun, "Fourier Descriptors with Different Shape Signatures: a Comparative Study for å," vol. 47, no. 50728503, 2011.

[13] "Kohei Arai and Yasunori Terayama, Polarized radiance from red tide, Proceedings of the SPIE Asia Pacific Remote Sensing, AE10-AE101-14, Invited Paper, 2010."

[14] "Kohei Arai, Red tides: combining satellite- and ground-based detection. 29 January 2011,SPIE Newsroom. doi: 10.1117/2.1201012.003267,http://spie.org/x44134.xml?ArticleID=x441 34.”
[15] C. J. Walsh, S. R. Leggett, B. J. Carter, and C. Colle, "Effects of brevetoxin exposure on the immune system of loggerhead sea turtles," Aquat. Toxicol. 97, no. 4pp. 293-303, 2010. doi:10.1016/j.aquatox.2009.12.014.

\section{Author PROFILE}

Cahya Rahmad: He received BS degrees from Brawijaya University Indonesia in 1998 and MS degrees from Informatics engineering at Tenth of November Institute of Technology Surabaya Indonesia in 2005. He is a lecturer in The State Polytechnic of Malang Since 2005. He received Doctoral degrees at Saga University japan in 2013, His interest researches are image processing, data mining and patterns recognition.

Kohei Arai: He received BS, MS and PhD degrees in 1972, 1974 and 1982, respectively. He was with The Institute for Industrial Science and Technology of the University of Tokyo from April 1974 to December 1978 and also was with National Space Development Agency of Japan from January, 1979 to March, 1990. During from 1985 to 1987, he was with Canada Centre for Remote Sensing as a Post Doctoral Fellow of National Science and Engineering Research Council of Canada. He moved to Saga University as a Professor in Department of Information Science on April 1990. He was a councilor for the Aeronautics and Space related to the Technology Committee of the Ministry of Science and Technology during from 1998 to 2000. He was a councilor of Saga University for 2002 and 2003. He also was an executive councilor for the Remote Sensing Society of Japan for 2003 to 2005. He is an Adjunct Professor of University of Arizona, USA since 1998. He also is Vice Chairman of the Commission A of ICSU/COSPAR since 2008. He wrote 33 books and published 510 journal papers. 